\title{
Homeopathic treatment for premenstrual symptoms
}

\author{
Angela Jones, DFFP, MFHom, General Practitioner and Medical Director, Luther Street Medical Centre, Oxford, UK
}

Correspondence: Dr A M Jones, Luther Street Medical Centre, PO Box 7, St Aldates, Oxford OX1 1TD, UK. Tel: +44 (0) 1865726008. Fax: +44 (0) 1865 204133. E-mail: angelajones@doctors.org.uk

(Accepted $1^{\text {st }}$ November 2002)

Journal of Family Planning and Reproductive Health Care 2002: 29(1): 25-28

\begin{abstract}
Premenstrual syndrome (PMS) and premenstrual dysphoric disorder (PMDD) are well-documented disorders causing significant morbidity in the female population. Treatments prescribed do not necessarily reflect proven clinical effectiveness. A recent systematic review from the Exeter Department of Complementary Medicine failed to endorse complementary therapies as a whole for treatment of PMS. However, a recent randomised controlled trial of homeopathic treatment for PMS confirms the clinical experience of homeopathic physicians that homeopathy is helpful in PMS.
\end{abstract}

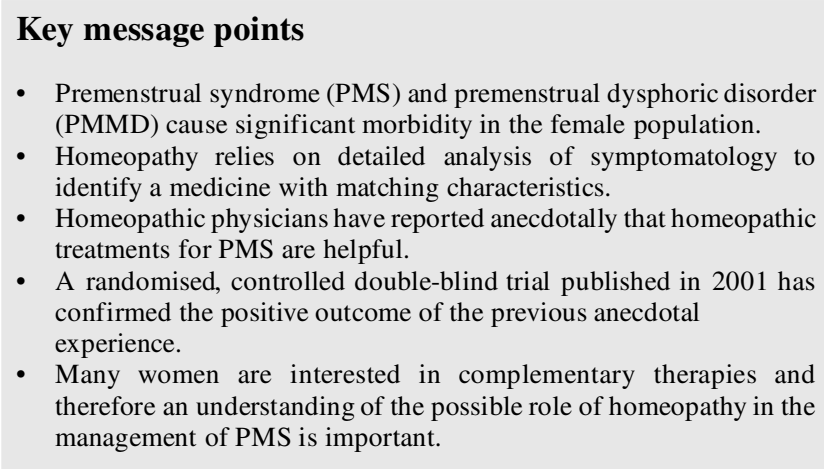

\section{Introduction}

Premenstrual syndrome (PMS) describes a constellation of symptoms that occur during the late luteal phase of the menstrual cycle and remit after the menses. These include generalised fluid retention, sensation of abdominal bloating, breast enlargement and breast tenderness plus mood disturbance and food cravings. When the mood disturbances (depressed mood, tension, labile affect, irritability, reduced impulse control) are severe, the syndrome is designated as premenstrual dysphoric disorder (PMDD).

Up to $75 \%$ of women report some premenstrual symptoms with approximately $10 \%$ suffering PMDD. ${ }^{1} \mathrm{~A}$ recently published survey of UK prescribing data for PMS between 1993 and $1998^{2}$ showed a general decrease in prescribing for this diagnosis, with progestogens, including progesterone, being the most widely prescribed, despite the lack of evidence demonstrating their efficacy. Selective serotonin re-uptake inhibitors (SSRIs), which were licensed for severe PMS/PMDD during this period, were the second most popular prescription. Vitamin B6 prescriptions dropped markedly, probably as a result of government recommendations on reduction of dosage.

There is also a whole range of physical illnesses that are known to be affected by the menstrual cycle in females. Menstrual cycle-related exacerbation of conditions such as migraine, diabetes, asthma, epilepsy and irritable bowel syndrome (IBS) are well-recognised ${ }^{3,4}$ and various therapeutic manipulations have been suggested, although none seem to have been the subject of definitive research.

\section{Use of complementary therapies}

Complementary therapies have been popular historically with women suffering from premenstrual symptoms. This is unsurprising given that until the introduction of the SSRIs, the only 'conventional' treatments were hormonal and, in the case of the progestogens, were not especially efficacious. A systematic review of the use of complementary therapies for premenstrual syndrome was published in 2001 by Stevinson and Ernst. ${ }^{5}$ Among the papers reviewed was one on homeopathy. The authors acknowledged some positive findings but found the evidence insufficiently 'compelling' to recommend any of the therapies.

However, in the same month, Yakir et al. published a pilot study on the effects of homeopathic treatment in women with PMS. ${ }^{6}$ This was a randomised, controlled, double-blind clinical trial. Twenty women from 20 to 48 years of age received individualised homeopathic treatment or placebo and their symptoms were scored using a daily menstrual distress questionnaire. Improvement of greater than $30 \%$ was observed in $90 \%$ of patients receiving active treatment and $37.5 \%$ receiving placebo $(\mathrm{p}=0.048)$. Although this trial probably needs to be repeated with larger numbers to improve its power, it is certainly encouraging and confirms the clinical impression gained by hundreds of medically qualified homeopathic physicians who find that homeopathy is a useful therapeutic approach for PMS.

\section{What is homeopathy?}

Homeopathy is a system of therapy that relies on a detailed analysis of an individual patient's symptomatology in order to identify a medicine with matching characteristics. If this medicine is then given in minute doses, it is said to act as a stimulus to the body's own healing processes and to eliminate the symptoms, and hence the disorder. As a therapeutic system it has been used for over 200 years. Indeed, until the advent of modern 'scientific' medicine, homeopathy was threatening to supersede the conventional treatments of the 19th and early 20th centuries both in Britain, Europe and the USA. ${ }^{7}$ Although it can never have the often overwhelming chemical effects of modern pharmacotherapy, homeopathy is still valued by both patients, and the physicians who use it, for its ability to address many illnesses and symptom complexes for which there is no answer in the standard formularies. In the UK, several hundred doctors hold qualifications in homeopathic medicine from the Faculty of Homeopathy, which oversees the training and examination of statutorily qualified health professionals in homeopathy. 


\section{Homeopathy and PMS/PMDD}

In textbooks describing the symptoms for which each homeopathic medicine is effective, the so-called 'materia medica', it is remarkable to find that all homeopathic medicines are described to relate to symptoms in many systems of the body, both physical and psychological. Thus it is possible to find, for instance, a medicine for headaches before menses, a distended abdomen before menses and great tearfulness before periods which responds to being comforted. The homeopathic medicine, Pulsatilla, is derived from the pasque flower, Pulsatilla nigricans. Conversely, the pattern of back pain before periods, cramping abdominal pains and a raging temper such that the woman feels as if she wants to stab someone (usually her partner) would be addressed by the medicine, Nux vomica, derived from the so-called marking nut, Strychnos nux vomica. Another well-known picture is that of increasing weariness and irritability before periods, accompanied by a desire to be left alone. This kind of subject usually suffers from a dragging low backache and, when the period finally arrives, it is often accompanied by dragging pains as if the womb is prolapsing. This symptom complex responds to the homeopathic medicine, Sepia, derived from the ink of the cuttlefish, Sepia officinalis.

Another important factor in deciding on a homeopathic medicine is how quickly the PMS symptoms settle after the onset of menstruation. In the case of Sepia, the symptoms usually last a few days into the period, before gradually dissipating. With Nux vomica, they may last a little longer. However, if a patient describes a PMS symptom complex that settles immediately at the onset of bleeding, the physician should consider prescribing Lachesis, derived from the venom of a South American snake. This medicine has the characteristic that it acts on symptoms that are improved by a 'discharge' of any kind, of which menstrual bleeding is an example.

Once the homeopathic physician has chosen the most suitable medicine, it is then usually taken over a few days at mid-cycle. If, by this method, the premenstrual symptoms are eliminated, it is possible to stop taking the medicine. It will often be a number of months, or even years, before the symptoms return. If the returning symptoms are identical to before, further doses of the same medicine can be taken until benefit is achieved. However, if the symptom complex has altered, then it is only logical that a different medicine, one that matches the new picture, will have to be chosen.

Finally, homeopathic treatment is well placed to address some of the more mysterious complaints such as premenstrual migraine, asthma, epilepsy and IBS. Medicines are recognised which can help with any of these complaints, specifically with a premenstrual aggravation. For instance, homeopathically prepared Sulphur or Zinc may be useful in the case of bronchial hypersensitivity, Cuprum (copper) and Pulsatilla (among others) are named as having an effect in convulsions before menses, and for premenstrual IBS, Nux vomica again, or Colocynthis (the bitter cucumber) or indeed one of 40 or 50 medicines listed may be prescribed.

It is worth knowing that the UK National Health Service funds prescription of homeopathic medicines and general practitioners and hospital doctors alike can prescribe on the usual prescription forms. Given the low cost of these medicines, and the fact that a long-term prescription is often not required, this method of management of PMS/PMDD
Just imagine if every time a young woman forgot to take her Cilest ${ }^{\circledR}$ oral contraceptive pill, she turned up at your surgery for advice. Without the Cilest ${ }^{\circledR}$ Helpline, that's just what might have happened.
We've offered support and advice to over $1 / 2$ million callers since the Helpline's launch - it's no wonder that so many doctors and young women have come to rely on Cilest ${ }^{\circledR}$

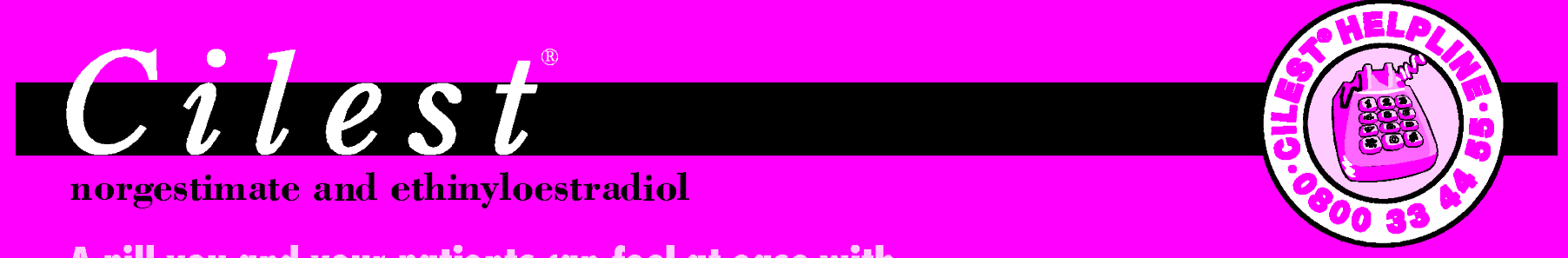

A pill you and your patients can feel at ease with

Cilest (norgestimate and ethimploestradiall, Abtrevinted Prescribing hifomation. (Plense refer to Sunmory of Product Charaderistis (smPC before prescribing). Presentudion:

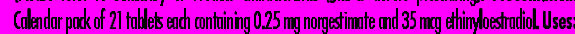
Oral controception. Dosage: One thblet daily for 21 dras followed by 7 tobletefree daxs. Controindikations, wonnings und precautions: Forful detribseeSmPC. Contro-indiantions: Pregnency

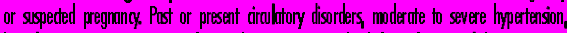

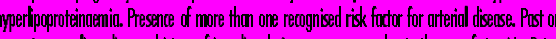
presert severe liver disense, history of juundice durimg pregnnny or due to the use of serrids, Ridor

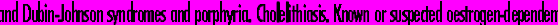

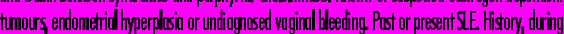

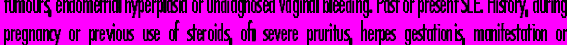

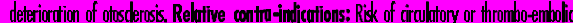

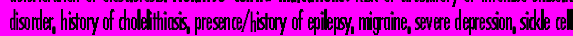

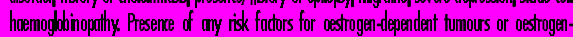

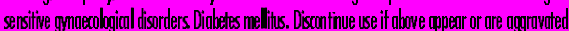
or it liver function tests herome alnormal Precuutions and worrings: Ohlorsm. Examintions and imvesigations it sont, then is deemed dinicaly approprinte. Post-partum atrinistution. Brenst

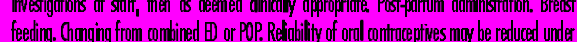

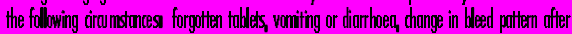

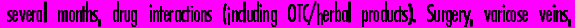
immobilistion. Adverse reactions: Most commonly reported in enily cydes of ord controceptive

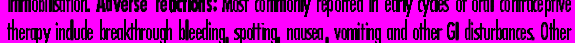

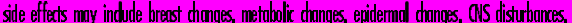
hypertension and coment discomfort it contand lenses are useat. Rarely: thromboembolic events, sex

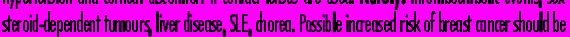
disussed with user and weighed against benefits of taking COS (see SmPC for detrils). Pudange quantities: 3 and 6 blister stips of 21 toblets. Prike: $\{6.42$ per $3 \times 21$ toblets $\{1284$ per $6 \times 21$

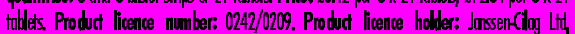
Sanderton, High Whyombe, Budkinghamsire IPI4 4HL, UK. Further information avolathle from

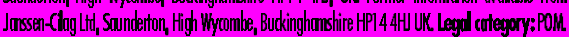

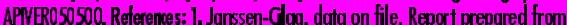
TMM. Dute of prepartion: Decenter 202.03336

TANSSEN-CILAG 
should be very cost effective in comparison with recurrent courses of hormones or SSRIs.

\section{Case studies}

Case 1

History: A 42-year-old woman, married with two teenage children. Presented with increasing mental distress before periods. Marked forgetfulness; had driven away from school gate without picking up children on more than one occasion. Increasing depression and feeling of hopelessness for last 6 months, always relieved within hours of period starting 'as if a huge weight was being lifted'. Also physical symptoms, in particular marked breast tenderness such that had to hold breasts when walking. Had resorted to oldfashioned binding of breasts in order to ease the pain. Low abdominal pain, alternating sides from month to month (probably ovarian). Heavy periods, cycle getting shorter (now 22 days). Had tried progesterone therapy for 6 months with no benefit. Evening primrose oil improved breast pain by about $25 \%$.

Treatment: Lac caninum given as a daily dose on Days 8, 9 and 10 (short cycle).

Outcome: Great improvement in all aspects after the first month of treatment. Stopped after 3 months. Recurrence 6 months later, treated straight away. Symptom-free thereafter for over 12 months. Stopped evening primrose oil with no ill effects.

\section{Case 2}

History: A 25-year-old clerk in building society, single. Presented with mood disturbance prior to periods. Irritable, moody, outbreaks of acne, from Day 21 until 3 days into menses. Causing difficulty at work, in that she had found it difficult to cope with colleagues and customers premenstrually. Had purchased vitamin B6 and evening primrose oil but no significant benefit. Not keen on hormonal manipulation in view of strong family history of thrombosis.

Treatment: Sepia given as a daily dose on Days 12, 13 and 14 for three cycles.

Outcome: No response.

Reassessment: Additional symptoms elicited. Sensation of 'water retention' also a feature; mood disturbance was predominantly brooding resentment of everyone around her leading to irritability and low mood; often cried when alone in the evenings; headaches and low backache also occurred at this time; skin generally greasy but acne only breaks out premenstrually.

Treatment: Natrum muriaticum given as a daily dose on Days 12, 13 and 14 for three cycles.

Outcome: Gradual improvement in mood, skin, headache and backache over the 3 months. Treatment represcribed for the next three cycles. At review, asymptomatic. Treatment discontinued and has not had to be repeated.

\section{Conclusions}

Homeopathy is one of the 'big five' established complementary therapies as recognised by the British Medical Association in its groundbreaking report on complementary therapies in 1993. Practitioners of homeopathic medicine find that it is an effective approach for the treatment of PMS. A recent pilot randomised controlled trial showed positive findings for homeopathic treatment in PMS and further research is in progress.

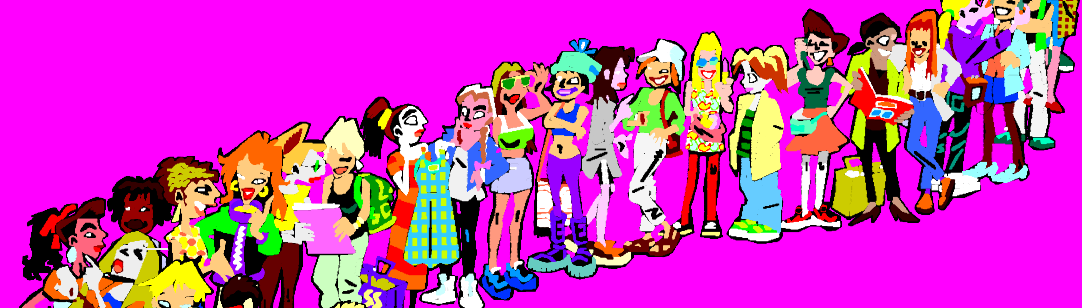
you this level of support

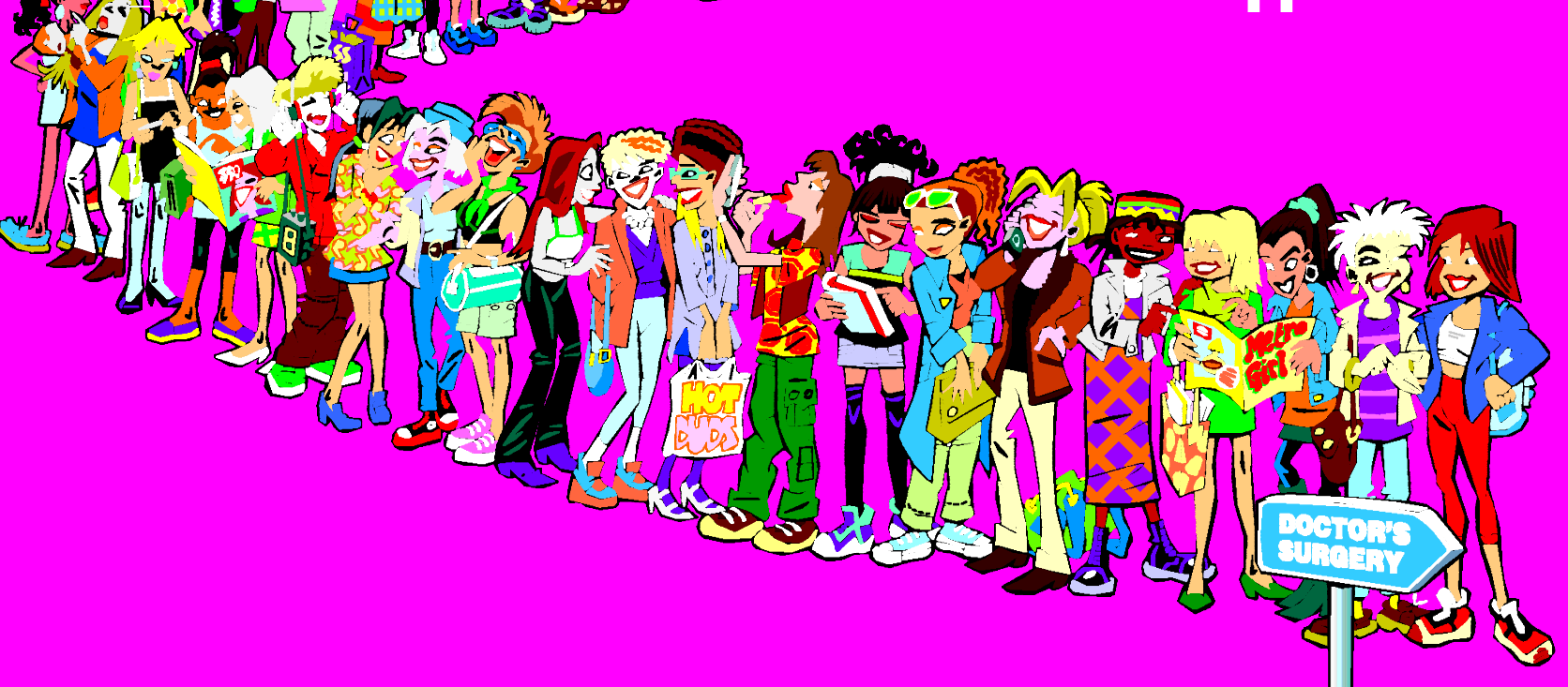




\section{Acknowledgements}

The author would like to thank the Faculty of Homeopathy for its professional support of herself and all homeopathic physicians. She would also like to acknowledge the HomInform Library at Glasgow Homeopathic Hospital for the ongoing development of its online search resource for homeopathic literature.

\section{Statements on funding and competing interests}

Funding. None identified.

Competing interests. None identified.

\section{References}

1 Elliott H. Premenstrual dysphoric disorder. A guide for the treating clinician. N C Med J 2002; 63: 72-75.

2 Wyatt KM, Dimmock PW, Frischer M, et al. Prescribing patterns in premenstrual syndrome. BMC Womens Health 2002: 2: 4.

3 Tan KS. Premenstrual asthma: epidemiology, pathogenesis and treatment. Drugs 2001; 61: 2079-2086.

4 Case AM, Reid RL. Menstrual cycle effects on common medical conditions. Compr Ther 2001; 27: 65-71.

5 Stevinson C, Ernst E. Complementary/alternative therapies for premenstrual syndrome: a systematic review of randomised controlled trials. Am J Obstet Gynecol 2001; 185: 227-235.

6 Yakir M, Kreitler S, Brzezinski A, et al. Effects of homeopathic treatment in women with premenstrual syndrome: a pilot study. Br Homeopath J 2001; 90: 148-153.

7 Nicholls PA. Homoeopathy and the medical profession. London: Croom Helm, 1988.

8 British Medical Association. Complementary medicine: new approaches to good practice. New York, NY: Oxford University Press, 1993.

Contact Information: The Faculty of Homeopathy, 15 Clerkenwell Close, London EC1R 0AA, UK. Tel: +44 (0) 171566 7810. Fax: +44 (0) 1715667815. www.trusthomeopathy.org

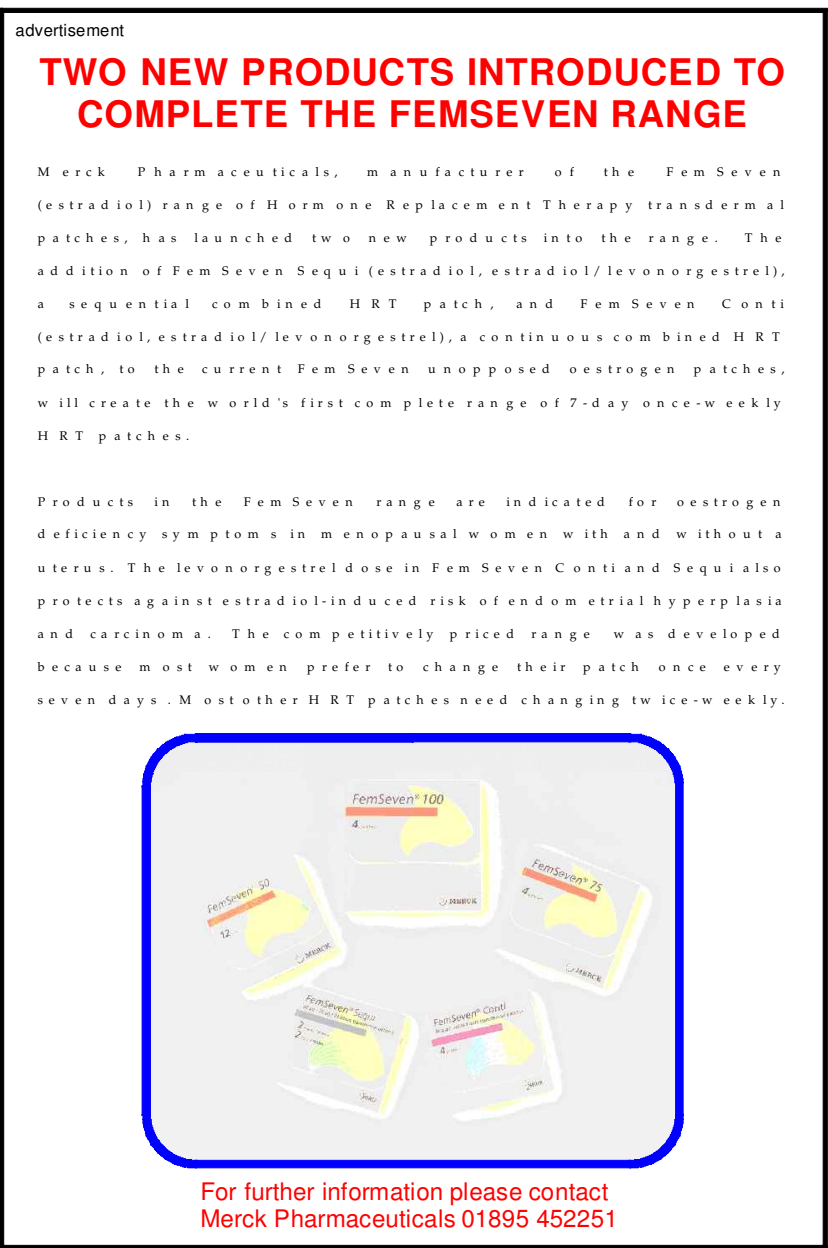

For further information please contact
Merck Pharmaceuticals 0189545225

\section{SERVICE DELIVERY}

\section{Can the Internet be used to improve sexual health awareness in web-wise young people?}

P C Goold, MB BS, MRCP, Specialist Registrar in Genitourinary Medicine (GUM), Department of GUM, Nottingham City Hospital NHS Trust, Nottingham, UK; M Ward, RGN, Health Advisor in GUM, Department of GUM, King's Mill Hospital, Sherwood Forest Hospitals NHS Trust, Sutton in Ashfield, UK; E M Carlin, MB ChB, FRCP, Consultant in GUM, Department of GUM, Nottingham City Hospital NHS Trust, Nottingham, UK and Department of GUM, King's Mill Hospital, Sherwood Forest Hospitals NHS Trust, Sutton in Ashfield, UK

Correspondence: Dr P C Goold, Department of Genitourinary Medicine, Nottingham City Hospital NHS Trust, Hucknall Road, Nottingham NG5 1PB, UK. Tel: +44 (0) 1159691169 ext 46746. Fax: +44 (0) 1159627684 . E-mail: pennygoold@aol.com

(Accepted $14^{\text {th }}$ November 2002)

Journal of Family Planning and Reproductive Health Care 2003; 29(1): 28-30

\begin{abstract}
Objectives. To assess Internet use amongst young people to determine whether it would be a practical way to provide sex education and information.

Methods. Year 10 students (aged 14-15 years) from North Nottinghamshire schools were asked to participate in focus groups to discuss the Internet. A series of predefined questions were directed to the whole group to generate debate. Areas explored included: Internet access and site; frequency and purpose of Internet use; websites visited; ideas
\end{abstract}

for a genitourinarymedicine (GUM) website. Responses were recorded by a hand count or as individual verbal responses. Results. Thirteen focus groups were held involving 287 students of approximately equal sex distribution. All had access to Internet facilities at school and 224 (78.0\%) had access elsewhere. Access was at least once a week by 178 (62.0\%) mostly for e-mail, games, chatlines and homework. No one accessed for health information. One hundred and seventy-nine (62.4\%) participants said they would use a GUM website. A 'question line' where they could e-mail 